\title{
Quantitative Southern blot analysis in the dystrophin gene of Japanese patients with Duchenne or Becker muscular dystrophy: a high frequency of duplications
}

\author{
Yoshiyuki Hiraishi, Shingo Kato, Tadayuki Ishihara, Toshiya Takano
}

\begin{abstract}
Eighty-four unrelated patients with Duchenne or Becker muscular dystrophy in Japan were studied by quantitative Southern blot analysis with dystrophin cDNA probes. We found partial deletions and duplications in $47(56 \%)$ and $12(14 \%)$ cases respectively by HindIII digestion. The duplications were confirmed by BgIII digestion and densitometric scanning. The frequency of duplications in this study is significantly higher than those previously reported. This may be because of the small sample number, the racial difference, or our quantitative methods. Our results suggest that attempts to detect duplications are important for a precise diagnosis. Both deletions and duplications clustered at the two hot spots as reported previously. Six cases were exceptions to the 'reading frame hypothesis'. We detected three types of HindIII RFLP. Based on the results of one duplication case, we propose a revised sequential order of exons in the cDNA10 region of the dystrophin gene. ( $f$ Med Genet 1992;29:897-901)
\end{abstract}

Duchenne muscular dystrophy (DMD) is a fatal $\mathrm{X}$ linked recessive disorder of children

Received 11 April 1992. Accepted 27 May 1992. with an incidence of approximately 1 in 3500 male births. ${ }^{1}$ Becker muscular dystrophy (BMD) is a less frequent, milder form and allelic to DMD. The $14 \mathrm{~kb}$ full length $\mathrm{cDNA}$ of the gene responsible for DMD and BMD has been cloned, ${ }^{2}$ which encodes a membrane associated protein of $430 \mathrm{kd}$ called dystrophin. ${ }^{3-6}$ The dystrophin gene is about $2.3 \mathrm{mil}-$ lion bp in size and consists of more than 75 exons. ${ }^{7}$ Partial deletions and, less frequently, partial duplications have since been reported in this gene. Although the frequencies of most of the reported deletions were in a range from $50 \%$ to $67 \%,{ }^{7-12}$ those of duplications varied from $0 \%$ to $6 \cdot 7 \% .^{71314}$ This variation may be in part because of difficulties in detecting duplications accurately by Southern blot analysis. We studied Japanese patients with DMD or BMD using quantitative Southern blot analysis and detected duplications in 12 $(14 \%)$ of 84 cases examined.

\section{Materials and methods}

SUBJECTS

Eighty-four unrelated Japanese male patients in the National Higashi-Saitama Hospital were examined, 79 with DMD, three with BMD, and two outliers. The criteria for clinical diagnosis were that patients become wheelchair bound before the age of 15 for DMD and after this age for BMD. For the outliers the criteria were becoming wheelchair bound before the age of 15 but surviving beyond the age of 30 without any life support systems.

\section{PROBES}

Dystrophin cDNA probes (cDNA1-2a, 2b-3, 4-5a, 5b-7, 8, 9-14) $)^{2}$ were obtained from the American Type Culture Collection. The probe cDNA9-14 was divided into five parts and subcloned; cDNA9 (7875-9080 bp), cDNA10 (9080-9713 bp), cDNA11 (9713-10905 bp), cDNA12 (10 905-11 $510 \mathrm{bp}$ ), and cDNA13-14 (11 510-13973 bp). The probe cDNA13-14 was not used as it contained repetitive sequences.

SOUTHERN BLOT ANALYSIS

DNA was extracted from peripheral blood leucocytes of patients as previously described. ${ }^{15}$ DNA concentrations were determined with a spectrophotometer. DNA was
Figure 1 Typical Southern blot analysis of the patients with DMD. The DNA of filter was hybridised with the probe $c D N A 8$. The sizes of the exon containing

fragments in $k b$ are shown on the right side of the autoradiograph. A junction fragment is shown by $(\mathfrak{J F})$. 
digested to completion with restriction endonuclease HindIII and, for duplication cases, $B g l$ II. Five micrograms of the digested DNA were electrophoresed in $0.7 \%$ agarose gel. The amount of DNA in each lane was equalised by comparing the intensity of the DNA smear stained with ethidium bromide on test runs. DNA in the gel was transferred to Hybond$\mathrm{N}+$ membrane (Amersham) and hybridised with ${ }^{32} \mathrm{P}$ labelled probes as previously described. ${ }^{16}$ The probes were labelled by the random hexanucleotide primed method ${ }^{17}$ and $50 \mathrm{ng}$ of the probe was used for one hybridisation. Post-hybridisation washes were carried out at $65^{\circ} \mathrm{C}$ in $1 \times \operatorname{SSPE}(0.15 \mathrm{~mol} / 1$ sodium chloride, $10 \mathrm{mmol} / \mathrm{l}$ sodium phosphate, pH $7 \cdot 4,1$ mmol/1 EDTA) containing $1 \%$ SDS. Membranes were exposed to $x$ ray film at $-70^{\circ} \mathrm{C}$ with intensifying screens for one to two days. The autoradiograph was scanned with a transmission densitometer (model CS-9000, Shimadzu, Kyoto, Japan). The membranes were rehybridised three to four times after the

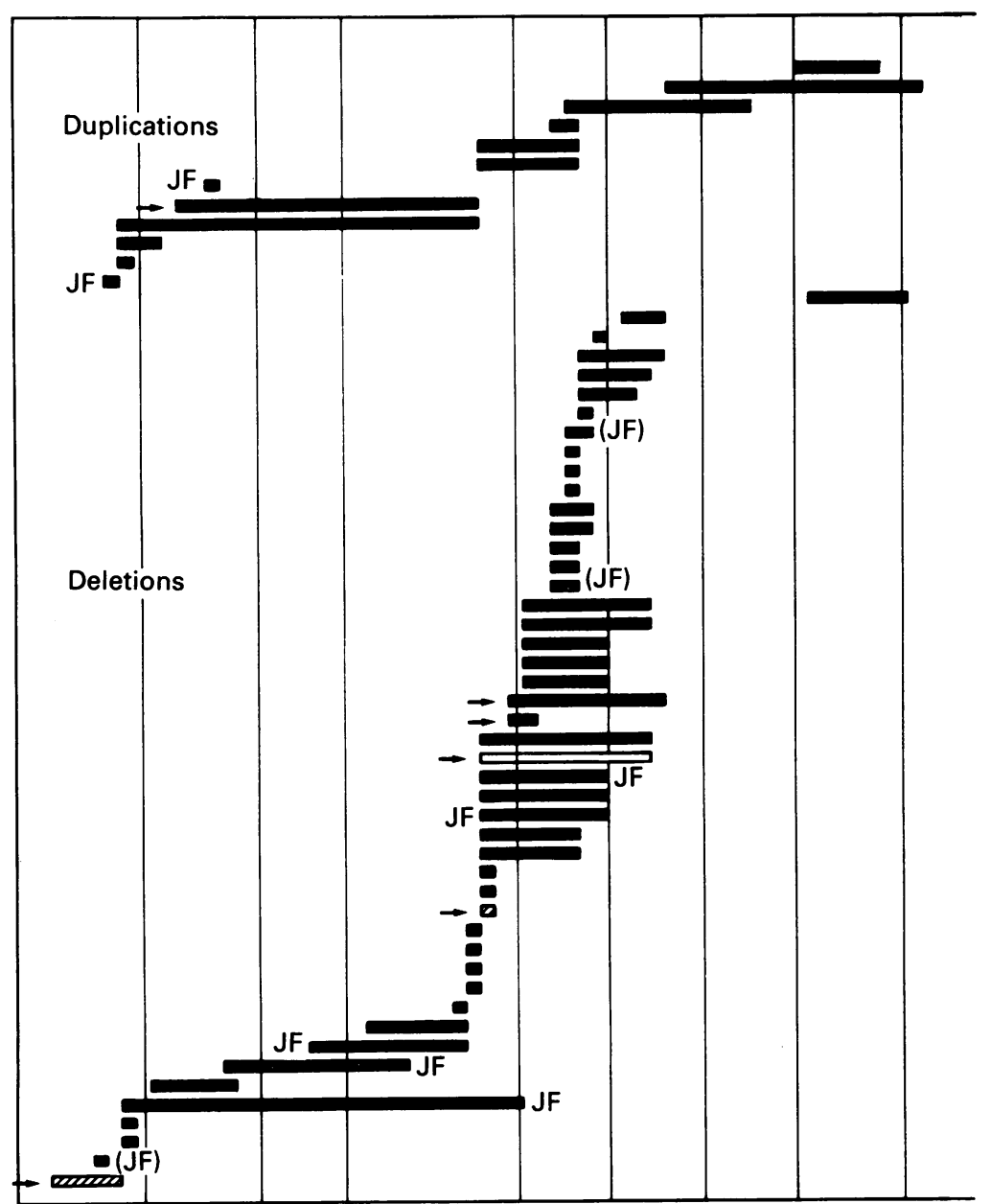

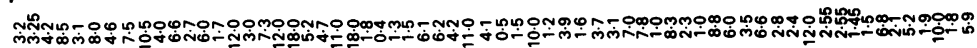

\begin{tabular}{|l|l|l|l|l|l|l|l|l|}
$1-2 a$ & $2 b-3$ & $4-5 a$ & $5 b-7$ & 8 & 9 & 10 & 11 & 12
\end{tabular}

Figure 2 Location and extent of deletions and duplications in the patients with DMD or BMD on the map of the dystrophin $c D N A$. The sequential order of the exon containing HindIII fragments is shown at the bottom; the order in the region of cDNA10 was revised by this study (see text). Open, closed, and hatched boxes represent DMD, BMD, and outliers, respectively. Cases carrying a junction fragment are shown by $\mathcal{F} F$ on either the right or left side, depending on which end was responsible for the generation of the junction fragment, or by $(\mathcal{F} F)$ when the side responsible was unable to be determined. The cases which are exceptions to the reading frame hypothesis (see Discussion) are shown by arrows. removal of probes by incubating in $0.4 \mathrm{~mol} / 1$ $\mathrm{NaOH}$ at $42^{\circ} \mathrm{C}$.

\section{Results}

DELETION ANALYSIS

We analysed HindIII digested DNA of the patients with each of the cDNA probes except for cDNA13-14. In 84 unrelated patients, we detected 47 intragenic deletions $(56 \%)$ including one in BMD and two in outliers. Fig 1 shows a typical example with the cDNA8 probe. Certain hybridising bands were not detected in cases $80,86,88$, and 89 as compared with the bands of a normal male. Case 79 had lost all the exons involved in cDNA8. In case 80 , two bands of 10.0 and $1.2 \mathrm{~kb}$ were deleted and a new band of $8.6 \mathrm{~kb}$ appeared. This fragment was thought to be a junction fragment, generated by a deletion of one of the restriction enzyme sites flanking an exon containing fragment. Eight junction fragments $(17 \%)$ were found in the deletions. Fig 2 summarises the location and the extent of the deletions on the map of exon containing HindIII fragments. ${ }^{70}$ The deletions were clustered in two regions: minor and major hot spots in the regions of cDNA1-2a and cDNA8, respectively. These results were consistent with those reported so far. ${ }^{2718}$

\section{DUPLICATION ANALYSIS}

By quantitative Southern blot analysis, we detected 12 intragenic duplications (14\%), all of which were in patients with DMD. Fig 3 shows typical results of cases carrying duplications. When HindIII digested DNA was analysed, the bands of 10.5 and $7.5 \mathrm{~kb}$ with cDNA1-2a in case 90 , those of 1.6 and $3.7 \mathrm{~kb}$ with the probe $\mathrm{CDNA} 8$ in case 58 , and those of $6 \cdot 6,6 \cdot 0,3 \cdot 5$, and $2 \cdot 8 \mathrm{~kb}$ with cDNA10 in case 70 were denser than the corresponding bands of a normal male control. These denser bands were contiguous on the cDNA map in each case (fig 2). To confirm these findings, we digested the DNA of these cases with another restriction endonuclease, $B g l \mathrm{II}$, and performed similar experiments. The partial correspondence between the HindIII and BglII exon containing fragments has been established. ${ }^{18}$ The $B g l$ II bands corresponding to the denser HindIII bands were also denser in all of 12 cases in which duplications were suggested by HindIII digestion. To determine the intensity of these bands, we scanned the autoradiographic films with a transmission densitometer. Typical densitometric scanning results and intensities of hybridisation bands are shown in fig 4 and the table, respectively. The bands in the suspected duplication were found to be twice as dense as the normal bands. Thus, we concluded that these denser bands represented partial gene duplications. The results are summarised on the map of exon containing HindIII fragments in fig 2. The duplications were clustered at the same hot spots as the deletions, but less frequently in the major hot spot. 


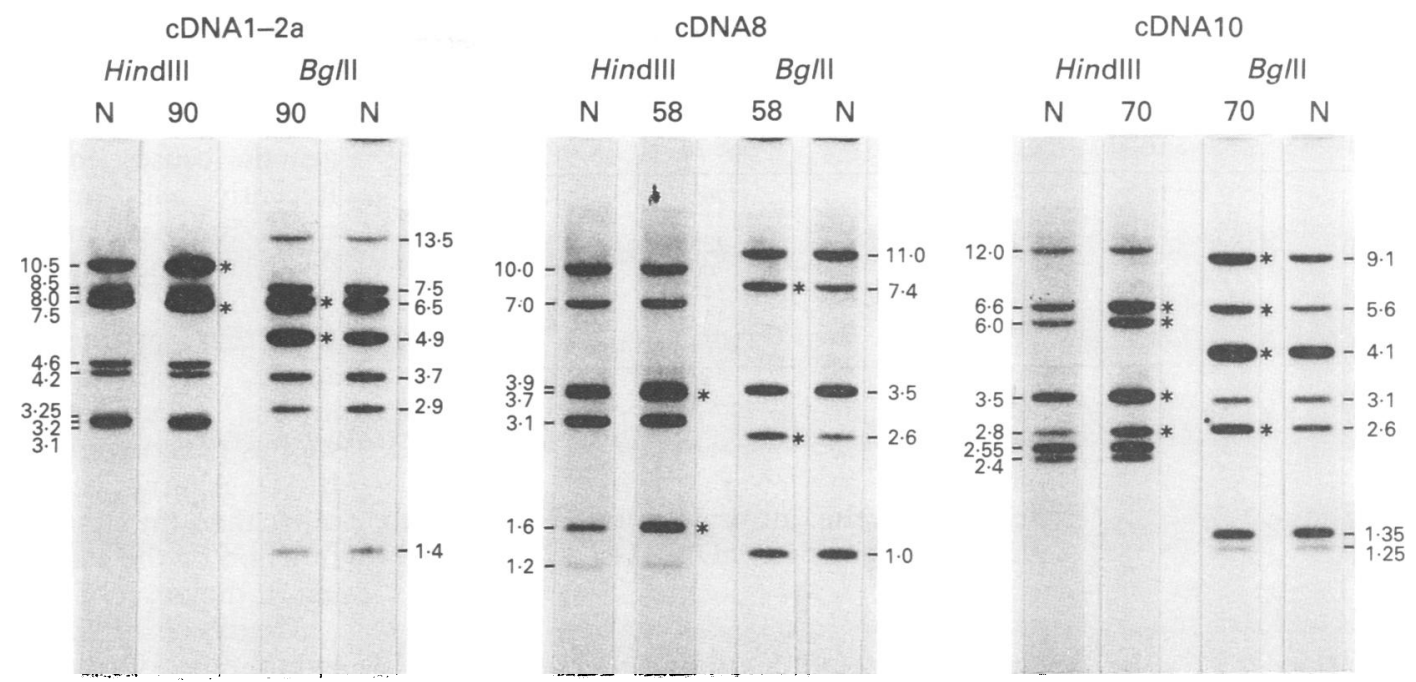

Figure 3 Typical Southern blot analysis of the patients carrying a duplication. The DNA of the patients (58, 70, and 90 ) and a normal male $(N)$ were digested with HindIII or BglII. The cDNA probes used for hybridisation were $c D N A 1-2 a$ for case 90, cDNA8 for case 58, and cDNA10 for case 70. The sizes of the exon containing fragments are shown at the side of the autoradiographs. The duplicated bands are shown by asterisks on the right.
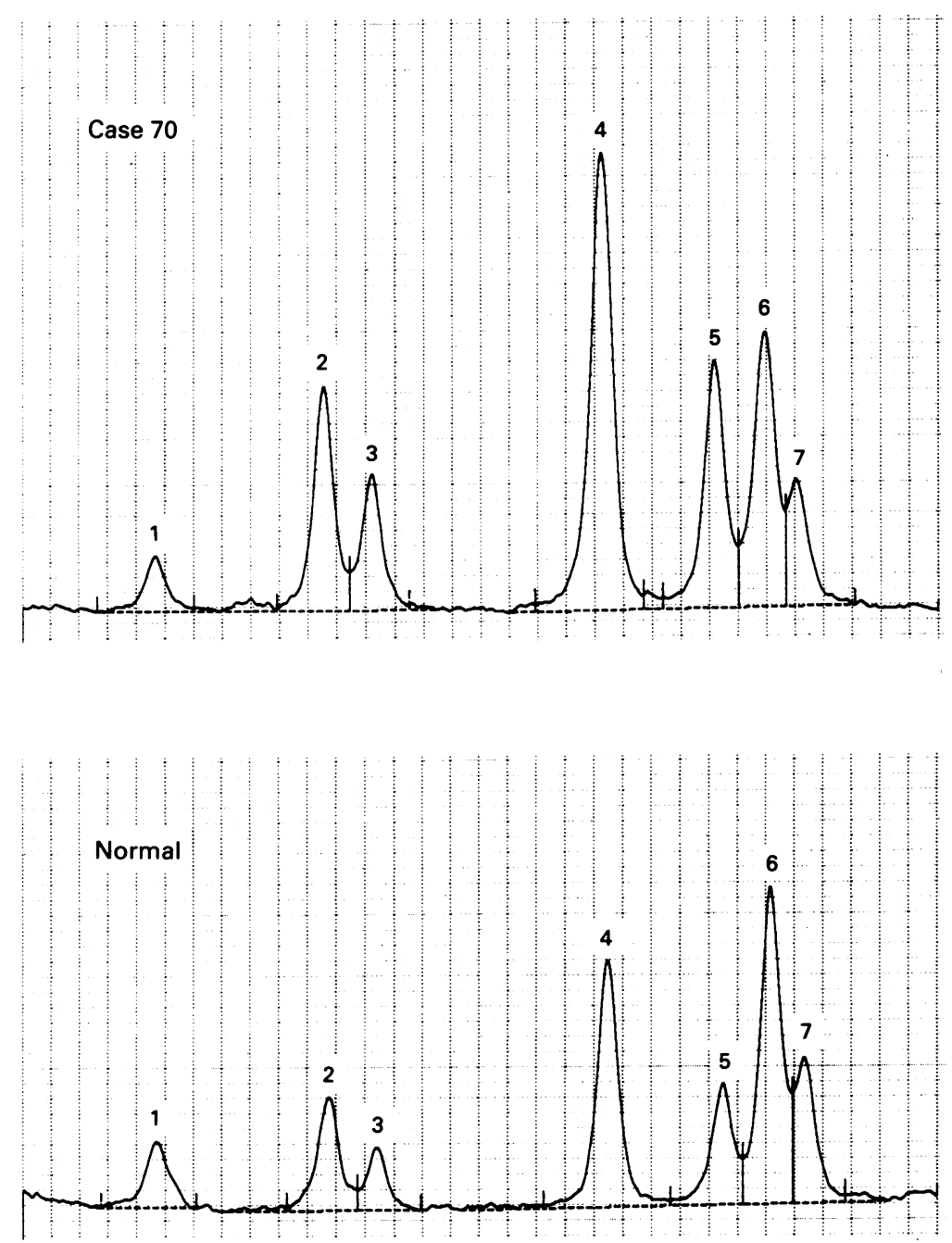

Figure 4 Densitometric scanning results for case 70 and a normal male. The autoradiographic film in fig 3 was used. The bands are numbered in order of size.

In two of the 12 cases carrying duplications, we detected HindIII bands of altered sizes. These bands were thought to be junction fragments accompanying duplications, since the probes used contained both the normal and the duplicated fragments and since the $B g l I I$ bands which corresponded to the duplicated HindIII bands and one of the flanking singlet HindIII bands were duplicated in both cases. The latter results gave us information on which end of the duplication regions was responsible for generation of the junction fragments (fig 2).

SEQUENTIAL ORDER OF HindIII FRAGMENTS IN cDNA10

In case 70 , the duplication extended into the region of cDNA10. The $6.6,6.0,3.5$, and $2 \cdot 8 \mathrm{~kb}$ HindIII bands were obviously duplicated, while the other bands of $12 \cdot 0,2 \cdot 55$, and $12.0 \mathrm{~kb}$ had normal intensities, as shown in fig 3. Den Dunnen et al reported that the $5^{\prime}$ and $3^{\prime}$ order of the HindIII fragments in CDNA10 were $6 \cdot 0,3 \cdot 5,2 \cdot 4,12 \cdot 0,6 \cdot 6,2 \cdot 8$, and $2.55 \mathrm{~kb}$. According to the order of HindIII fragments they proposed, case 70 must carry two independent duplications within a small region, but this seems unlikely. The 6.6 and $2.8 \mathrm{~kb}$ fragments should precede those of 2.4 and $12.0 \mathrm{~kb}$. We propose a revised order of HindIII fragments in this region, as shown in fig 2 .

HindIII RFLPs

In Southern blot analysis of HindIII digested DNA of the patients, we found three types of RFLP in the dystrophin gene: $2 \cdot 5,2 \cdot 7$, and $5.3 \mathrm{~kb}$ fragments in three, two, and one patients with the probes CDNA1-2a, 11, and 11 , respectively. The major alleles corresponding to each one were $3 \cdot 1,2 \cdot 55$, and $6 \cdot 8 \mathrm{~kb}$ in size. One of the patients carried two minor alleles of 2.5 and $2.7 \mathrm{~kb}$. The sizes of $B g l \mathrm{II}$ fragments corresponding to these RFLPs were not changed. The cases containing these minor alleles had a deletion or a duplication of different regions, suggesting that these fragments are not junction fragments. This is the second report of HindIII RFLPs in the dystrophin gene. A HindIII RFLP with CDNA1-2a was reported with alleles $8 \cdot 3 / 7 \cdot 5 \mathrm{~kb} .{ }^{19}$ However, we are not able to rule out the possibility that a 
Intensity of hybridising bands in case 70 and a normal male in fig 4. The area under each peak which was automatically calculated in arbitrary units with the densitometer is shown.

\begin{tabular}{lcrrc}
\hline Band & Size $(\mathrm{kb})$ & Normal & Case 70 & Case 70/normal \\
\hline 1 & $12 \cdot 0$ & 9570 & 7262 & 0.76 \\
2 & $6 \cdot 6$ & 15010 & 27332 & 1.82 \\
3 & $6 \cdot 0$ & 7159 & 16287 & $2 \cdot 27$ \\
4 & $3 \cdot 5$ & 32493 & 62700 & 1.93 \\
5 & $2 \cdot 8$ & 15918 & 32347 & 2.03 \\
6 & $2 \cdot 55$ & 40244 & 36453 & 0.91 \\
7 & $2 \cdot 4$ & 16802 & 15070 & 0.90 \\
\hline
\end{tabular}

deletion in the intron generated the $5.3 \mathrm{~kb}$ HindIII fragment in cDNA11.

\section{PHENOTYPE AND READING FRAME}

We studied the correlation between disease phenotype and the changes in reading frame caused by deletions or duplications in our cases. The cases with a junction fragment were excluded from this analysis since it was not possible to identify the deleted or duplicated exon. ${ }^{10}$ In DMD, the reading frame was disrupted in 43 cases, including 37 with a deletion and six with a duplication, but maintained in the other three cases carrying a deletion (fig 2). In all of the three BMD cases and outliers, the reading frame was disrupted (fig 2). It was noteworthy that one BMD case and one outlier carried a deletion of the same HindIII fragments as deleted in DMD cases (fig 2).

\section{Discussion}

We performed quantitative Southern blot analysis to detect deletions and duplications in the dystrophin gene of 84 Japanese patients with DMD or BMD. The frequency of duplications in this study, $14 \%$, was remarkably higher than those reported by others: $6.7 \%$ and $5.5 \%$ by Den Dunnen et $a l$ and $\mathrm{Hu}$ et $a l,{ }^{14}$ respectively. This difference may be because of the small sample number in our study, the sensitive and quantitative methods we used for the analysis, or the racial characteristics of the Japanese. Sugino et $a l^{20}$ and Asano et $a l^{21}$ reported similar studies on Japanese patients, but they did not set out to find duplications. Our results as well as others showed that duplications comprise a significant fraction of the genetic lesions in DMD and BMD. Therefore, the detection of these in the dystrophin gene should not be ignored in the molecular diagnosis of DMD and BMD. Recently, multiplex PCR has been developed, which is able to amplify several deletion prone exons simultaneously. ${ }^{22-24}$ This technique will be very useful for the first screening of $D M D / B M D$ patients. However, it is very difficult to diagnose patients with duplications and carriers, since the present technique of PCR cannot determine the quantity of the target DNA accurately.

We detected neither deletions nor duplications in $30 \%$ of the patients examined, which is similar to other studies in which both deletions and duplications were analysed..$^{714}$
About $70 \%$ is probably the upper limit for the detection of these genetic lesions by Southern blot analysis with cDNA probes. What are the genetic causes in the remaining patients? Recently, point mutations causing premature transcriptional termination were reported in the dystrophin gene of patients with DMD. ${ }^{25} 26$ Matsuo et $a l^{7}$ detected a 52 bp deletion in exon 19. Other possible genetic disorders, for example, mutations in the promoter region, introns, or unidentified exon sequences, as well as gene inversion, may cause DMD and $\mathrm{BMD}$. Alternatively, lesions in certain genes other than the dystrophin gene may affect the function or the stability of dystrophin resulting in the onset of DMD and BMD.

Monaco $e t a l^{8}$ proposed the reading frame hypothesis for the aetiology of DMD and BMD; the translational reading frame of the dystrophin gene is disrupted, resulting in the production of truncated and inactive dystrophin in DMD, while the reading frame is not disrupted and the function of dystrophin partially remains in BMD. We identified six cases which were exceptions to this hypothesis in the 46 patients carrying a deletion or a duplication but no junction fragment, three cases of DMD whose reading frames were not disrupted and three cases of BMD and outliers in which frameshifts occurred. Similar exceptions have also been reported by others..$^{7-1029}$ In addition, we found two cases of BMD and outlier that carried a deletion of the same exons as deleted in DMD. Forrest et $a l^{30}$ and Baumbach et $a l^{8}$ reported similar observations. These findings show that the disease phenotype is not dependent only on the deletion of specific exons.

This study was supported in part by a Research Grant (2A-3) for Nervous and Mental Disorders from the Ministry of Health and Welfare, Japan.

1 Emery AEH. Duchenne muscular dystrophy. In: Motulsky AG, Harper PS, Bobrow M, Scriver C, eds. Oxford monographs on medical genetics. No 15. Oxford: Oxford monographs on medical

2 Koenig M, Hoffman EP, Bertelson CJ, Monaco AP, Feener C, Kunkel LM. Complete cloning of the Duchenne muscular dystrophy (DMD) cDNA and preliminary genomic organization of the DMD gene in normal and affected individuals. Cell 1987;50:509-17.

3 Hoffman EP, Brown RH Jr, Kunkel LM. Dystrophin: the protein product of the Duchenne muscular dystrophy locus. Cell 1987;51:919-28.

4 Sugita $\mathrm{H}$, Arahata $\mathrm{K}$, Ishiguro $\mathrm{T}$, et al. Negative immunostaining of Duchenne muscular dystrophy (DMD) and $m d x$ muscle surface membrane with antibody agains synthetic peptide fragment predicted from DMD cDNA. Proc Japan Acad 1988;64, Ser B:37-9.

5 Watkins SC, Hoffman EP, Slayter HS, Kunkel LM. Immunoelectron microscopic localization of dystrophin in myofibres. Nature 1988;333:863-6.

6 Zubrzycka-Gaarn EE, Bulman DE, Karpati G, et al. The Duchenne muscular dystrophy gene product is localized in sarcolemma of human skeletal muscle. Nature in sarcolemma

7 Den Dunnen JT, Grootscholten PM, Bakker E, et al. Topography of the Duchenne muscular dystrophy (DMD) gene: FIGE and CDNA analysis of 194 case reveals 115 deletions and 13 duplications. Am 7 Hum Genet 1989;45:835-47.

8 Baumbach LL, Chamberlain JS, Ward PA, Farwell NJ, Caskey CT. Molecular and clinical correlations of deletions leading to Duchenne and Becker muscular dystrophies. Neurology 1989;39:465-74.

9 Gillard EF, Chamberlain JS, Murphy EG, et al. Molecula and phenotypic analysis of patients with deletions within the deletion-rich region of the Duchenne muscular dystrophy (DMD) gene. Am $\mathcal{F}$ Hum Genet 1989;45:507-20.

10 Koenig M, Beggs AH, Moyer M, et al. The molecular basis for Duchenne versus Becker muscular dystrophy: correlation of severity with type of deletion. Am $\mathcal{f}$ Hum Genet 1989;45:498-506. 
11 Cooke A, Lanyon WG, Wilcox DE, et al. Analysis of Scottish Duchenne and Becker muscular dystrophy families with dystrophin cDNA probes. $\mathcal{F}$ Med Genet 1990; 27:292-7

12 Upadhyaya M, Smith RA, Thomas NST, Norman AM Harper PS. Intragenic deletions in 164 boys with
Duchenne muscular dystrophy (DMD) studied with dysDuchenne muscular dystrophy (DMD) studied

$13 \mathrm{Hu}$ X, Burghes AHM, Ray PN, Thompson MW, Murphy EG, Worton RG. Partial gene duplication in Duchenn and Becker muscular dystrophies. F Med Genet 1988; 25:369-76.

14 Hu X, Ray PN, Murphy EG, Thompson MW, Worton RG Duplicational mutation at the Duchenne muscular dystrophy locus: its frequency, distribution, origin, and phenotype genotype correlation. Am f Hum Genet 1990; 46:682-95.

15 Herrmann BG, Frischauf AM. Isolation of genomic DNA Methods Enzymol 1987;152:180-3.

16 Kato S, Tachibana K, Takayama N, Kataoka H, Yoshida MC, Takano T. Genetic recombination in a chromosomal translocation $\mathrm{t}(2 ; 8)(\mathrm{p} 11 ; \mathrm{q} 24)$ of a Burkitt's lymphoma cell translocation $\mathrm{t}(2 ; 8)(\mathrm{p} 11 ; \mathrm{q} 24)$ of a Burkits
line, KOBK 101. Gene 1991;97:239-44.

17 Feinberg AP, Vogelstein B. A technique for radiolabeling DNA restriction endonuclease fragments to high specific

18 Darras BT, Blattner P, Harper JF, Spiro AJ, Alter S, Francke U. Intragenic deletions in 21 Duchenne muscuar dystrophy (DMD)/Becker muscular dystroph (BMD) families studied with the dystrophin cDNA: location of breakpoints on HindIII and BglII exoncontaining fragment maps, meiotic and mitotic origin of the mutations. Am f Hum Genet 1988;43:620-9.

19 Davies KE, Mandel JL, Monaco AP, Nussbaum RL, Willard HF. Report of the committee on the genetic constitution of the X chromosome. Cytogenet Cell Genet 1991; 58:853-966.

20 Sugino S, Fujishita S, Kamimura N, et al. Moleculargenetic study of Duchenne and Becker muscular dystrophies: deletion analyses of 45 Japanese patients and segrephies: deletion analyses of 45 Japanese patients and segre-
gation analyses in their families with RFLPs based on the data from normal Japanese females. Am $\mathcal{f}$ Med Genet 1989;34:555-61.

21 Asano J, Tomatsu S, Sukegawa K, et al. Gene deletions in Japanese patients with Duchenne and Becker muscular dystrophies: deletion study and carrier detection. Clin dystrophies: deletion

22 Chamberlain JS, Gibbs RA, Ranier JE, Nguyen PN, Caskey CT. Deletion screening of the Duchenne muscular dystrophy locus via multiplex DNA amplification. Nucleic Acids Res 1988;16:11141-56.

23 Beggs AH, Koenig M, Boyce FM, Kunkel LM. Detection of $98 \%$ of DMD/BMD gene deletions by polymerase chain reaction. Hum Genet 1990;86:45-8.

24 Chamberlain JS, Gibbs RA, Ranier JE, Caskey CT. Multiplex PCR for the diagnosis of Duchenne muscular dystrophy. In: Innis MA, Gelfand DH, Sninsky JJ, White TJ, eds. PCR protocols: a guide to methods and Whications. San Diego: Academic Press, 1990:272-81.

25 Bulman DE, Gangopadhyay SB, Bebchuck KG, Worton RG, Ray PN. Point mutation in the human dystrophin gene: identification through Western blot analysis. Genomics 1991;10:457-60.

26 Roberts RG, Bobrow M, Bentley DR. Point mutations in the dystrophin gene. Proc Natl Acad Sci USA 1992; 89:2331-5.

27 Matsuo $M$, Masumura $T$, Nakajima $T$, et al. A very small frame-shifting deletion within exon 19 of the Duchenne muscular dystrophy gene. Biochem Biophys Res Commun 1990;170:963-7.

28 Monaco AP, Bertelson CJ, Liechti-Gallati S, Moser H, Kunkel LM. An explanation for the phenotypic differences between patients bearing partial deletions of the DMD locus. Genomics 1988;2:90-5.

29 Malhotra SB, Hart KA, Klamut HJ, et al. Frame-shift deletions in patients with Duchenne and Becker muscular dystrophy. Science 1988;242:755-9.

30 Forrest SM, Cross GS, Speer A, Gardner-Medwin D, Burn J, Davies KE. Preferential deletion of exons in Duchenne and Becker muscular dystrophies. Nature 1987;329:638-40. 